\title{
Topological ion channel noise and its implications for the neuronal dynamics Marifi Güler
}

Address: Department of Computer Engineering, Eastern Mediterranean University, Famagusta, Mersin-10, Turkey

Email: Marifi Güler - marifi.guler@gmail.com

from Seventeenth Annual Computational Neuroscience Meeting: CNS*2008

Portland, OR, USA. 19-24 July 2008

Published: II July 2008

BMC Neuroscience 2008, 9(Suppl I):P48 doi:I0.II86/I47I-2202-9-SI-P48

This abstract is available from: http://www.biomedcentral.com/I47I-2202/9/SI/P48

(c) 2008 Güler; licensee BioMed Central Ltd.

We have recently established a dual viewpoint of ion channel noise asserting that conformational changes in ion channels are actually exposed to two different kinds of fluctuations [1], namely the intrinsic noise and the topological noise. The intrinsic noise is associated with the stochasticity in the movement of gating particles between the inner and the outer faces of the membrane. The topological noise, on the other hand, is associated with the fluctuations emerging from the uncertainty in accessing the permissible topological states of open gates. In a toy membrane just having three potassium channels (twelve gates), for example, nine open gates can be configured into a variety of topological states with the possible results that none of the channels is open, one is open, or two are open.

A simultaneous and mutually interactive description of the two kinds of noise can be formulated using Nelson's stochastic when open to dissipative environments, and subsequently the voltage dynamics can be worked out through the use of reduced density operator techniques [1]. This results in the arousal of renormalizations of the membrane capacitance and of a voltage dependent potential function. The resultant computational neuron model, scrutinized using a special membrane with some tailored properties giving the Rose-Hindmarsh dynamics in the

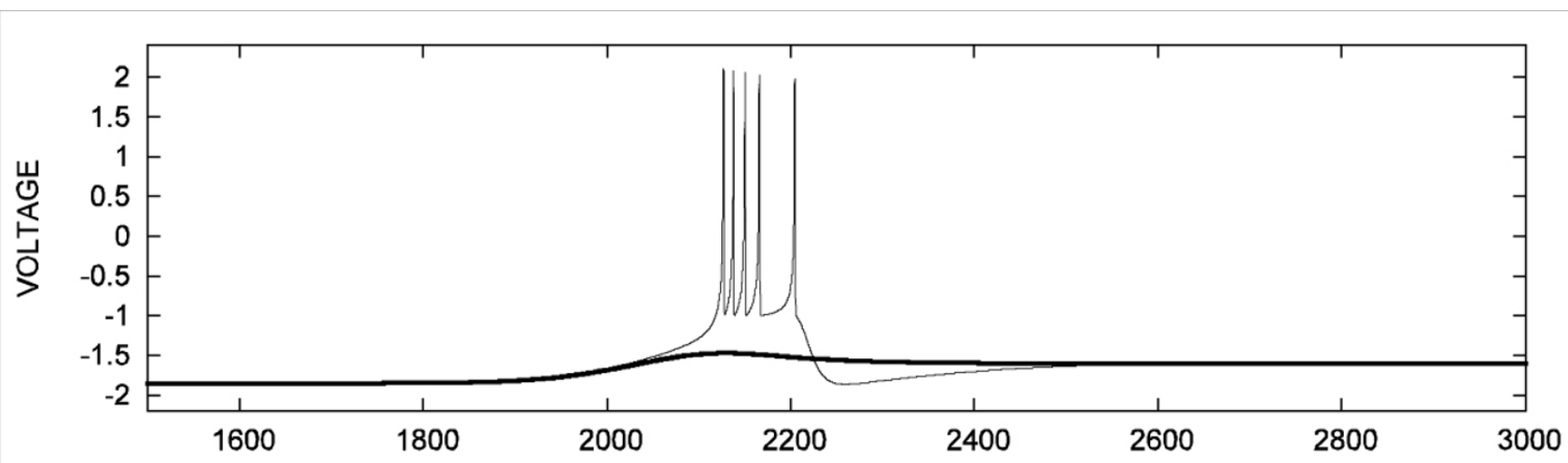

Figure I

Time series of voltage in response to a rapid increase in the input current from $-\mathrm{I}$ to 0 in the neighborhood of time $=2000$.

The units are dimensionless. The thin and the thick lines correspond to the dynamics in the presence and absence, respectively, of the renormalization corrections. 
deterministic limit, has been investigated in detail numerically for its dynamics for time-independent input currents [2]. It was found that the intrinsic noise gives rise to two significant coexisting effects: it initiates spiking activity even in some range of input currents for which the corresponding deterministic model is quiet and causes bursting in some other range of input currents for which the deterministic model fires tonically. The renormalization corrections, which would not arise in the absence of topological noise, augment the above behavioral transitions from quiescence to spiking and from tonic firing to bursting, and, therefore, the bursting activity takes place in a wider range of input currents for larger values of the correction coefficients.

In this presentation, we will address main aspects of the topological noise and review earlier results on its implications. Moreover, we report here for the first time that the presence of the renormalization corrections enables detection of a rapid momentary increase in the input current by causing a transient above threshold activity in the form of bursting (see Figure 1).

\section{References}

I. Güler M: Dissipative stochastic mechanics for capturing neuronal dynamics under the influence of ion channel noise: Formalism using a special membrane. Phys Rev E 2007, 76:041918(17).

2. Güler M: Detailed numerical investigation of the dissipative stochastic mechanics based neuron model. J Comput Neurosci 2008 in press. accepted for publication.
http://Www.biomedcentral.com/1471-2202/9/S1/P48

Publish with Biomed Central and every scientist can read your work free of charge

"BioMed Central will be the most significant development for disseminating the results of biomedical research in our lifetime. " Sir Paul Nurse, Cancer Research UK

Your research papers will be:

- available free of charge to the entire biomedical community

- peer reviewed and published immediately upon acceptance

- cited in PubMed and archived on PubMed Central

- yours - you keep the copyright

Submit your manuscript here:

http://www.biomedcentral.com/info/publishing_adv.asp 